\title{
Concepções e práticas de oralidade na escola básica na perspectiva dos docentes ${ }^{1}$
}

\author{
Tânia Guedes Magalhães²
}

Ana Paula de Oliveira Lacerda ${ }^{3}$

\begin{abstract}
Resumo
Esta pesquisa analisou as concepções de ensino de oralidade docentes, participantes de curso de formação. Como metodologia, utilizamos o questionário aberto para analisar as concepções e as práticas pedagógicas realizadas em sala de aula, bem como as dificuldades enfrentadas. Os resultados revelam que há avanços, em relação a outras pesquisas, nas concepções e práticas pedagógicas, visto que aparecem nas respostas a) a relevância do ensino de oralidade para a formação cidadã; b) a necessidade de proposição de situações de interação; c) gêneros orais na prática de ensino. Todavia, tais dados revelam também que há esforços a empreender no tocante a) à compreensão da oralidade como uso e reflexão linguística; b) às dificuldades materiais; e c) à falta de formação docente.

Palavras-chave: Oralidade; Concepções de professores; Formação docente.
\end{abstract}

Conceptions and practices of orality in basic school by teacher's perspective

\section{Abstract}

This study has analyzed the conceptions of orality teaching of participants in a training course. As methodology, the open questionnaire was used in order to analyze the conceptions and pedagogical practices carried out in the classroom, as well as the difficulties faced. The results show advances, related to other researches, in the conceptions and pedagogical practices, as appears in the answers a) the relevance of teaching orality to citizen formation; b) the necessity for bringing up interactional situations; c) oral genres in teaching practice. Nonetheless, such data also reveal some efforts to be undertaken to (a) the understanding of orality as linguistic use and reflection; b) material difficulties; and c) lack of teacher training.

Keywords: Orality; Teacher conceptions; Teacher training.

\section{Introdução}

Concepções atribuídas à oralidade por professores de diversas etapas de ensino tem sido tema de pesquisas nos últimos anos, juntamente com investigações sobre as potencialidades e desafios acerca da oralidade como objeto de ensino (PALMIERI, 2005; MAGALHÃES, 2006; BUENO, 2009; LEAL, BRANDÃO, NASCIMENTO, 2010; COSTA-MACIEL, 2011; ÁVILA, NASCIMENTO, GOIS, 2012; GALVÃO, AZEVEDO, 2015; BAUMGÄRTNER, 2015; MACHADO, 2017).

\footnotetext{
${ }^{1}$ Esta pesquisa foi desenvolvida no âmbito do Projeto “Oralidade, gêneros textuais e ensino" coordenado pela 1a autora (financiamento pela Universidade Federal de Juiz de Fora).

${ }^{2}$ Universidade Federal de Juiz de Fora. Juiz de Fora. Endereço Eletrônica: tania.magalhaes95@gmail.com

${ }^{3}$ Universidade Federal de Juiz de Fora. Juiz de Fora. Endereço Eletrônica: ana.lacerdajf@gmail.com
}

$$
\text { Periódico Horizontes - USF - Itatiba, SP-Brasil - e019004 }
$$


Fruto de uma tradição da supremacia da escrita, não apenas na sociedade em geral como também da própria instituição escolar, o pressuposto de que a oralidade não é passível de ensino sistematizado e com reflexão linguística figurou durante anos. Mais recentemente, em novas investigações sobre a relação oralidade - letramento, esta concepção foi desmitificada, trazendo repercussões teórico-metodológicas frutíferas para inovações nas práticas escolares, bem como possíveis mudanças nos materiais didáticos, nos documentos oficiais e na formação de professores, tema enfocado neste trabalho.

No fluxo dessas discussões, apresentamos os resultados de uma pesquisa realizada com professores em curso de formação continuada, realizado em 2017, cujo objetivo foi compreender as concepções de ensino de oralidade de professores da escola básica, refletindo também sobre os desafios e as possibilidades reais de trabalho com o oral em diferentes disciplinas do ensino fundamental e médio. Trabalho anterior (MAGALHÃES, 2006) analisa concepções de ensino de oralidade de professores de 60 ao 90 ano, pesquisa com a qual dialogamos neste momento. Pretendemos analisar, com professores da mesma cidade, os possíveis avanços na formação e as repercussões de pesquisas sobre oralidade nas concepções e práticas docentes.

A necessidade de ampliar as investigações sobre oralidade na formação de professores está posta em diversos trabalhos, como os de Galvão e Azevedo (2015), Palmieri (2005) e Baumgärtner (2015), por exemplo, que encontram concepções docentes que não resultam, ainda, num trabalho escolar de efetivo desenvolvimento de capacidades para interagir em sociedade via modalidade oral, objetivo importante no ensino de língua materna. Vale destacar que essas concepções são atribuídas à formação precária, não havendo uma atribuição de culpa aos docentes, postura com a qual concordamos.

Para tanto, apresentamos, neste trabalho, questões relativas à relação oralidade letramento e ensino para, em seguida, abordar pesquisas sobre oralidade e formação de professores. Após, descrevemos brevemente a metodologia de trabalho, que envolveu coleta de dados em um curso de extensão realizado na Universidade Federal de Juiz de Fora. Depois da apresentação dos dados, em que construímos sentidos para as concepções, desafios e

Periódico Horizontes - USF - Itatiba, SP-Brasil - e019004 
potencialidades de trabalho com a modalidade oral na escola, apresentamos brevemente o relato de práticas docentes realizadas ao longo deste curso. Pretendemos contribuir com mais uma discussão acerca da oralidade na formação continuada de professores.

\section{Pressupostos teóricos \\ Oralidade e ensino}

A concepção de oralidade que trazemos para este trabalho é a perspectiva do continuum oralidade-letramento (MARCUSCHI, 2001) em que oralidade e letramento são práticas sociais de uso da língua, e fala e escrita são modalidades de uso dessa língua, contrários à dicotomia entre modalidades e rompendo com o mito da grande divisão (ONG, 1983). Articulamos essa perspectiva aos preceitos de Corrêa, sobre a heterogeneidade da escrita (ROJO, SCHNEUWLY, 2006; CORRÊA, 2001).

A relação oralidade e escrita sofreu uma virada em sua concepção tradicional. Até os anos 80 do século passado, a escrita era considerada superior à oralidade. Rojo e Schneuwly (2006) afirmam ainda que

Tinha-se, anteriormente, na concepção de oralidade e escrita como contrários, a ideia de que a primeira era usada apenas em contextos informais enquanto a outra para formais. Via-se a fala como desorganizada, variável, heterogênea e a escrita como lógica, racional, estável, homogênea; a fala seria não-planejada e a escrita, planejada e permanente; a fala seria o espaço do erro e a escrita, o da regra e da norma, enquanto a escrita serviria para comunicar à distância no tempo e no espaço; a fala somente aconteceria face a face; a escrita se inscreveria, a fala seria fugaz; a fala é expressão unicamente sonora; a escrita, unicamente gráfica (ROJO; SCHNEUWLY, 2006).

Com novos estudos, oralidade e letramento são consideradas práticas sociais em que fala e escrita estão imbricadas em função das ações de linguagem produzidas por diferentes sujeitos nas mais diversas situações. Por ser a fala apropriada num processo natural independente da escolarização, e por haver, ainda, em nossa sociedade, o mito da supremacia da escrita, acreditase que o ensino de oralidade é desnecessário, visto que os alunos já "sabem falar", fato que

Periódico Horizontes - USF - Itatiba, SP-Brasil - e019004 
restringe as atividades escolares quase sempre à escrita, quando muito em leitura voz alta ou discussões de temas propostos (oralidade integrada) onde a produção final, na maioria das vezes, retorna à escrita.

Com essa visão mais ampla da relação fala e escrita, diferentes autores defendem que escola deve incluir metodologias específicas envolvendo ações para o ensino da oralidade por meio dos gêneros orais conjugadas com práticas de letramento (MARCUSCHI, 2001; LEAL, GOIS, 2012). Documentos oficiais e materiais didáticos também se apropriam dessa defesa. Todavia, estudos demonstram que embora a oralidade esteja posta como conteúdo e prática de ensino, ela é sempre apresentada na perspectiva do déficit, em que "há menos gêneros orais do que escritos nos livros, os documentos subestimam as práticas de oralidade, bem como há poucos materiais disponíveis para o ensino de oralidade" (BUENO; ABREU, 2010; LEAL; GOIS, 2012; BUENO; COSTA-HÜBES, 2015).

Dolz, Schneuwly e Haller (2004, p. 199) definem que a perspectiva do oral autônomo toma os gêneros orais "como objetos de ensino e aprendizagem em si. Não constituem um percurso de passagem para aprendizagem de outros comportamentos linguísticos (a escrita ou a produção escrita) ou não-linguísticos (em relação com outros saberes disciplinares). Também não estão subordinados a outros objetos de ensino-aprendizagem". Nessa perspectiva, defendese que o aluno deve interagir como sujeito ativo nas situações sociais ultrapassando "as formas de produção oral cotidiana para confrontar com outras formas mais institucionais, mediadas, parcialmente reguladas por restrições exteriores" (DOLZ; SCHNEUWLY; HALLER, 2004, p. 175).

Desse modo, a concepção de ensino de oralidade que a toma como objeto de ensino (oralidade autônoma) proporciona o uso social da língua e a reflexão sobre ela (RANGEL, 2010); diversos gêneros orais estão a serviço da interação social, bem como são passíveis de descrição e análise em função das situações de produção criadas na escola/sociedade, desenvolvendo capacidades de linguagem para a ação discente. Debates, discursos de formatura, seminários, conferências, entrevistas, tutoriais, notícias e reportagens são gêneros pelos quais os alunos sabem interagir? O que aprendem na produção e na análise desses gêneros? Que reflexões linguísticas o estudo dessas situações discursivas pode proporcionar?

Periódico Horizontes - USF - Itatiba, SP-Brasil - e019004 
Para que possamos implementar um ensino de oralidade, investir na formação inicial e continuada de professores é uma medida bastante profícua. No tocante à formação inicial, é necessário baseá-la em conceitos de língua e linguagem fundados em seu caráter social e interacional, promovendo oportunidades para que os graduandos possam interagir em espaços sociais reais por gêneros orais (ouvir palestras, participar de exposições, teatros e debates, apresentar trabalhos de pesquisa ou expor banners em eventos, participar de assembleias e agremiações dentre outros). Isso permitiria refletir sobre essas produções, o que acreditamos ser uma decisão acertada para que as vivências de linguagem, apreendidas pela experiência, pudessem reverberar na escola. Dessa forma, os alunos teriam a oportunidade de presenciar e de se apropriar de conhecimentos acerca dos comportamentos linguísticos e interacionais exigidos nessas situações (MIRANDA, 2005). Na formação continuada, precisamos analisar que concepções os docentes trazem de sua formação e de suas práticas para traçar planejamentos colaborativos que nos levem a novas formas de desenvolver ações formativas de educação da oralidade.

Como formação inicial e continuada de professores devem ser foco de discussão e problematização, passamos abordá-las na seção seguinte.

\section{Concepções e formação docentes para o ensino da oralidade}

As pesquisas apresentadas aqui mostram que, embora teoricamente tenhamos avançado para uma concepção que integra oralidade e letramento, fomentando um equilíbrio entre atividades de fala e de escrita na escola, a formação de professores revela, ainda, concepções condizentes com o mito da supremacia da escrita, com a relação entre fala e escrita como (in)formalidade, bem como ausência de uma concepção discursiva de linguagem, em que os usos sociais e a reflexão sobre a língua são objetivos do ensino de língua portuguesa.

Palmieri (2005) desenvolveu pesquisa num curso de graduação em Letras - Português, numa universidade privada, no interior de São Paulo. A pesquisa envolveu os alunos no início do curso e os mesmos alunos nos períodos finais, momento em que vários, inclusive, já eram

Periódico Horizontes - USF - Itatiba, SP-Brasil - e019004 
docentes. Após entrevista com eles, as respostas dos alunos aos questionamentos revelam, pelo menos, quatro concepções sobre o oral: a) oral como fala; b) oral como modalidade dependente da norma escrita; c) oral como espaço do lúdico e do espontâneo; d) oral em sua multiforme dimensão enunciativa. Nos dados, apenas a 4a concepção, embutida nas respostas dos alunos, estava relacionada a um trabalho escolar que envolvesse produção oral em situações relevantes e reflexão sobre a língua em função dos usos sociais.

A investigação de Magalhães (2006), em pesquisa realizada com professores do ensino fundamental, mostra resultado de entrevistas sobre práticas de oralidade na escola na cidade de Juiz de Fora. Todos os sete professores entrevistados declararam trabalhar com oralidade. Todavia, duas categorias foram recorrentes nos dados: a) usar a língua falada e b) analisar a língua falada. Sobre o item a, usar a língua falada, as concepções e práticas orais revelaram finalidades e ações como vencer a timidez, dar recado, conversar, discutir questões em grupo, dizer o que entendeu do texto, mudar o final da história; os docentes também relataram que os alunos são bastante falantes. Essa é a perspectiva do oral integrado, acima descrito. Ainda vemos, nessas entrevistas, uma associação entre oralidade, informalidade e erro, bem como uma concepção de ensino de oralidade como conversação livre, discussão (sobre conteúdo dos textos escritos) e oralização da escrita.

Em relação ao item b, reflexão/análise da língua, foram encontradas questões que relacionam oralidade com vícios de linguagem; também há relato de práticas de registrar a fala de colegas, fazer transcrição e analisar as relações (semelhanças e diferenças) entre fala e escrita, não em função do certo e errado, mas ao que é apropriado para os contextos. Apenas uma professora mencionou questões de análise, enfocado os usos mais apropriados para oralidade e para a escrita em função da situação. Não figuram, nesta pesquisa, os gêneros orais, o que interpretamos como ausência de situações mais sistematizadas de produção oral, como seminários, entrevistas, debates, jornal falado etc. Vale destacar que, nesta época, a proposta curricular da Secretaria de Educação da Prefeitura Municipal de Juiz de Fora era extremamente falha no eixo da oralidade 4 .

${ }^{4}$ Magalhães; Ferreira (2014).

Periódico Horizontes - USF - Itatiba, SP-Brasil - e019004 
Bueno (2009), contribuindo com pesquisas na formação de professores e nas práticas pedagógicas, elenca razões que impedem um trabalho com gêneros orais de forma mais sistematizada. A maior parte das respostas dos docentes, segundo sua pesquisa, é a "pouca informação teórica ou metodológica sobre o trabalho com gêneros orais"; outras razões são a falta de vontade de professores, a própria concepção de supremacia da escrita, falta de políticas educacionais e editoriais, existência de conteúdos mais importantes e falta de formação na graduação. Algumas dessas razões são, também, encontradas em nossos dados, que comentaremos na seção 3 deste artigo.

Uma investigação, cujo resultado encontra-se no texto "Basta conversar? A prática de ensino da oralidade no segundo ciclo", que também tematizou a prática de docentes com a oralidade, foi a realizada por Leal, Brandão e Nascimento (2010), em uma análise de 75 aulas de cinco professoras do $7^{\circ}$ ano do Ensino Fundamental. Ainda que as docentes tenham reconhecido a importância da oralidade no ensino, as atividades não ultrapassavam conversas e discussões. Tarefas que focalizavam o oral formal, bem como o planejamento da fala não foram encontradas, o que resultou na ausência de estudo sistemático de gêneros orais nos dados desta pesquisa. Mais uma vez, a perspectiva do oral autônomo não está, de forma plena, nas concepções e práticas docentes.

Costa-Maciel também traz colaborações no quesito ensino de oralidade. Os resultados publicados em 2011 mostram uma pesquisa feita com docentes dos 3ㅇ ao 5o ano do Ensino Fundamental que investigou se há momentos reservados para o trabalho com a oralidade, as demandas desse eixo de ensino e a avaliação das atividades. Sinteticamente, os resultados giram em torno de leituras coletivas, conversa sobre o conteúdo textual e oralização da escrita. As demandas para o trabalho com a oralidade advêm também, de timidez e necessidade de uso de uma fala mais polida, bem como aprendizado de regras sociais. Há ainda certa dependência da oralidade à norma padrão e ao sistema de escrita.

Já Galvão e Azevedo (2015), em recente pesquisa realizada com docentes, analisaram se os textos orais são utilizados como objeto de ensino no desenvolvimento das práticas comunicativas dos alunos em sala de aula. A partir de 12 entrevistas, os dados revelaram que os

Periódico Horizontes - USF - Itatiba, SP-Brasil - e019004 
docentes ainda não têm clareza das noções teóricas sobre a oralidade que os possibilitem realizar ações didáticas canalizadas para a formação de alunos linguisticamente competentes.

No tocante a pesquisas referentes ao período de alfabetização, Machado (2017) faz uma análise inicial em documentos elaborados por docentes em formação continuada no programa Pacto Nacional pela Alfabetização na Idade Certa (PNAIC) em Santa Catarina. A análise do corpus, coletado no relato de orientadoras de estudo, uma das funções do PNAIC, permite entrever que a presença de atividades de oralidade centra-se em "perguntar ao aluno o que entendeu do texto", ou seja, como afirmam os autores da escola de Genebra,

embora a linguagem oral esteja bastante presente nas salas de aula (nas rotinas cotidianas, na leitura de instruções, na correção de exercícios, etc) afirma-se que ela não é ensinada, a não ser incidentalmente, durante atividades diversas ou pouco controladas". Assim como denunciam didatas sociólogos, linguistas e formadores de professores, o ensino escolar da língua oral e de seu uso ocupa atualmente um lugar limitado (DOLZ; SCHNEUWLY; HALLER, 2004, p. 149).

Ou seja, não há uma proposta sistemática e recorrente que pense a progressão em gêneros orais, envolvendo uso e reflexão sobre a língua, eixos centrais no ensino de língua materna, o que envolveria situações reais de comunicação, incluindo conhecimento da situação comunicativa, preparação para a fala, produção e reflexão sobre a produção, com vistas ao desenvolvimento das capacidades de linguagem para agir socialmente. Entretanto, Machado revela haver uma sensibilização, durante o curso de formação citado, sobre o trabalho pedagógico potencial para a aprendizagem da oralidade, como "organização de seminário e ou mesa-redonda para debater temas de interesse da turma; apresentação de telejornal com notícias sobre os temas de debate; participação de narrativas (reais e ou imaginárias); socialização de experiências do cotidiano da criança; organização de momentos culturais que favoreçam o desenvolvimento da oralidade (MACHADO, 2017, p. 112). Nesses casos, poderiam ser desenvolvidas tarefas de reflexão sobre os usos sociais da língua falada em diferentes contextos, envolvendo aspectos multimodais (questões corporais, faciais e gestuais envolvidas nas produções dos alunos).

Vemos, com essas pesquisas, que é recorrente a percepção de que a formação é Periódico Horizontes - USF - Itatiba, SP-Brasil - e019004 
necessária para implementar inovações no trabalho docente com a oralidade.

Constatando, então, tais dificuldades e algumas lacunas no trabalho com a oralidade, já atestada em diferentes pesquisas, Baumgärtner (2015) realiza importante trabalho de formação continuada de docentes dos anos iniciais para romper com essa tradição. Do ano de 2006 em diante, o "Grupo de estudos em Língua Portuguesa - GELP: uma experiência de formação continuada de professores com foco em gêneros orais e ensino" foi realizada com professores da Educação Básica no Oeste do Paraná, que tinha o propósito de efetivar um diálogo entre universidade e escola, com a participação voluntária de professores. A proposta de problematizar questões relativas ao ensino de LP nos anos iniciais gerou encontros mensais e presenciais, com duração de $8 \mathrm{~h}$ cada. Os resultados materiais, entre outros, foram 4 cadernos pedagógicos publicados pela Associação Municipal do Oeste do Paraná.

A partir de estudo teórico, levantamento de gêneros prescritos no currículo da rede, bem como proposta de construção coletiva de um material para realização de prática de oralidade na escola, os docentes relataram, ao longo da pesquisa, certas dificuldades e inseguranças, bem como impressões de estarem fazendo "coisas abstratas e distantes da realidade" (BAUMGÄRTNER, 2015, p. 102). Em suas primeiras análises de gêneros orais, as docentes enfocaram o material verbal, excluindo os aspectos multimodais (imagem, som, movimento, iluminação, enquadramento). Ao longo da pesquisa, também encontraram dificuldades, em seus contextos escolares, como falta de disponibilidade de equipamentos, desconhecimento ou dificuldades quanto ao manuseio de tecnologias de áudio e vídeo (gravadores, filmadoras); e falta de exemplares dos possíveis gêneros a serem trabalhos na sala. Todavia, a pesquisadora revela grande apropriação de conhecimentos durante a elaboração da proposta, o que vai ao encontro de nossas expectativas quando da realização de programas formativos que se oponham ao sentimento comum de docentes, de impotência e frustração, quando lidam com materiais cujo conteúdo revela conhecimento distante de sua formação e realidade (KLEIMAN, 2008).

Nesse sentido, vemos que essas pesquisas revelam a ausência de formação específica para a oralidade, bem como discussões sobre as potencialidades de práticas educativas com gênero orais na escola, reforçamos o ideal de desenvolvimento de trabalhos com professores,

Periódico Horizontes - USF - Itatiba, SP-Brasil - e019004 
em que ações interventivas sejam realizadas em grupos de discussão, conforme o relatado por Baumgärtner, em que os docentes possam dialogar sobre suas conquistas em experiências nas escolas, com possibilidades de rica troca de saberes, com vistas à reconstrução de suas práticas. Nessa direção, apresentamos a metodologia do trabalho que desenvolvemos em curso de extensão em 2017 na UFJF.

\section{Aspectos metodológicos}

A pesquisa foi realizada durante um curso de extensão da UFJF, intitulado "Letramentos e práticas escolares", durante o ano de 2017. Tal curso teve a duração de 45 horas, para o qual ingressaram 35 docentes de 1ㅇ ao 9o ano do Ensino Fundamental e 1으 ao 3으 do Médio de diferentes componentes curriculares. Os docentes enviaram uma carta justificando sua intenção de frequentar o curso, o que permitiu ter um panorama bastante diversificado de disciplinas escolares e etapas de ensino ${ }^{5}$. O curso foi dividido em três grandes módulos, com $15 \mathrm{~h}$ cada, enfocando, primeiramente, aspectos mais gerais sobre aprendizagem e concepções de linguagem; em seguida, o 2 ㅇ módulo abordou práticas de oralidade na escola, sob nossa responsabilidade ${ }^{6}$ e a 3 a etapa tematizou sobre letramentos, gênero e sexualidade.

Realizamos uma pesquisa qualitativa, na vertente da Linguística Aplicada, em que se pretende construir sentidos para o discurso docente, subjacentes aos dados (MOREIRA; CALEFE, 2006), colhidos por meio de questionários respondidos por 28 dos 35 professores matriculados no curso. O questionário continha 5 questões sobre oralidade, além de uma que buscava descrever a etapa de atuação. Nas orientações dadas inicialmente aos professores para

\footnotetext{
${ }^{5}$ Fizeram parte do grupo 28 professores, dos quais 5 que atuavam na Educação Infantil; 19 professores que atuavam nos anos iniciais (1으 ao 50 anos); 6 professores atuavam no Ensino Fundamental II e Ensino Médio; e 3 professores eram técnicos, supervisores ou coordenadores, não atuando diretamente na sala de aula (em alguns casos, professores relataram atuar em duas modalidades, como muitos que trabalhavam com El e 1으 ao 5응 anos concomitantemente). As áreas de atuação eram Língua Portuguesa: 11 professores; Matemática: 9 professores; Ciências: 3 professores; Espanhol, Geografia, História e Artes: 1 professor em cada área; Educação Física ou projetos de esporte: 2 professores; todas as disciplinas (10 ao 50 ano): 4 professores.

${ }^{6}$ Sob responsabilidade da $1^{\mathrm{a}}$ autora deste artigo, com assessoria da $2^{\mathrm{a}}$ autora, bolsista do referido curso.
}

Periódico Horizontes - USF - Itatiba, SP-Brasil - e019004 


\section{HSE}

responder ao questionário, durante o 1 ํ dia do módulo do curso, enfatizamos que não era necessária a preocupação com respostas "certas ou erradas", mas que fossem enfocadas as reais práticas desenvolvidas por eles. Essas práticas seriam lidas e em seguida discutidas no próprio curso, para que efetivamente pudéssemos avançar na formação dos professores, com base nas dificuldades e nas experiências reais dos docentes, o que foi feito de forma muito proveitosa, relatada na 4ạ seção deste trabalho.

\section{Os dados ${ }^{7}$}

A apresentação dos dados, que foram colhidos de 5 perguntas feitas aos docentes pelos referidos questionários, será feita em cinco subseções, nas quais mencionamos as porcentagens relativas às respostas, além de construir possíveis sentidos para as concepções e práticas docentes, a partir do nosso arcabouço teórico.

\section{Concepções de oralidade}

A primeira pergunta, que solicitava ao professor uma abordagem com base em sua compreensão acerca das "práticas de oralidade na escola", o maior número de respostas se refere a falar livremente, num total de 12 professores. Os seguintes exemplos, retirados dos questionários, demonstram isso:

\footnotetext{
- "permitir que os alunos expressem opiniões"8

- "ouvir os colegas"

- "os alunos precisam aprender a relatar"

- "conversar com os colegas"

- "trocar ideias"
}

\footnotetext{
${ }^{7}$ O motivo pelo qual algumas medidas ultrapassam 100\% é que, como das 5 questões, 4 eram abertas, as respostas se duplicam em vários questionários, já que os docentes poderiam descrever suas atividades em sala, apresentar relatos sobre suas práticas bem como suas concepções de aprendizagem e oralidade.

${ }^{8}$ Respostas retiradas de cinco questionários.
}

Periódico Horizontes - USF - Itatiba, SP-Brasil - e019004 
Ou seja, $42 \%$ de docentes aderem à ideia de que "basta falar", conforme Leal, Brandão e Nascimento. Essas respostas são condizentes com as práticas relatadas na 5 a pergunta, em que se pede aos docentes que descrevam uma ação desenvolvida por ele na escola, como um projeto ou uma sequência de exercícios (que será comentado mais à frente).

Em seguida a essa, o 2ㅇ maior número de respostas se refere a propostas com gêneros textuais orais: $25 \%$ concebem os gêneros orais como situações para aprender a interagir oralmente, em que "os alunos devem ser colocados em situações de debates e apresentações orais" ${ }^{\prime}$, por exemplo. Observamos também a citação de outros gêneros, como seminários e entrevistas nas respostas. Nelas, vemos justificativas para a necessidade de "adequação da fala ao contexto e ao interlocutor", bem como menção a aspectos gestuais e de expressão facial. O quadro abaixo permite visualizar as respostas em porcentagens:

Quadro 1 - síntese de respostas da questão 1

\begin{tabular}{|l|c|}
\hline Falar livremente & $42 \%$ \\
\hline Interagir pelos gêneros orais & $25 \%$ \\
\hline A oralidade tem menos valor que a escrita & $10,7 \%$ \\
\hline Oralidade = informalidade e escrita = formalidade & $7,1 \%$ \\
\hline Não trabalha diretamente com oralidade; outras respostas & $15,2 \%$ \\
\hline
\end{tabular}

Fonte: elaborado pelas autoras

Essas respostas condizem com os resultados de Palmieri (2005), em que há concepções de oral como fala, como lugar do lúdico e do espontâneo e de modalidade dependente da norma escrita. Percebemos, também, um número, ainda que pequeno, que já se sensibiliza e retrata um trabalho com a oralidade na perspectiva dos gêneros orais, envolvendo uma preparação, a produção oral adequada aos aspectos discursivos (interlocutores, por exemplo), bem como uma possível reflexão linguística sobre a produção, o que não foi relatado pelos docentes.

Em relação a essa primeira pergunta, acreditamos que o discurso oficial, os cursos de formação e os materiais didáticos podem ter impactado o trabalho docente. Isso porque em 2006, na pesquisa anteriormente realizada (MAGALHÃES, 2006), o termo "gêneros orais" sequer

\footnotetext{
${ }^{9}$ Resposta retirada de um questionário

Periódico Horizontes - USF - Itatiba, SP-Brasil - e019004
} 
fora mencionado. Conforme listamos na 3a seção deste artigo, o uso de que se falava nas entrevistas referia-se ao oral integrado, como responder exercícios, comentar os textos etc, o que se revela aqui novamente. Contudo, percebemos certo avanço visto que os gêneros textuais orais figuram, agora, como uma possibilidade que extrapola a interação canônica da sala de aula, envolvendo debates, entrevistas, seminários, entre outros. De que forma essa transposição dos gêneros ocorre deve-se analisar cuidadosamente, o que não foi nosso foco no momento desta pesquisa.

\section{Dificuldades enfrentadas no trabalho com a oralidade}

Em relação às dificuldades encontradas para desenvolver práticas de oralidade na escola, segundo os docentes, a maior parte dos professores declara a falta de conhecimento e formação para essa especificidade. Essa resposta apareceu em 35,7\% dos questionários, um número significativo a nosso ver. O quadro abaixo permite visualizar as respostas em porcentagens.

Quadro 2 - síntese de respostas da questão 2

\begin{tabular}{|l|c|}
\hline Falta de conhecimento e de formação & $35,7 \%$ \\
\hline O currículo impede (pouco tempo para todos os conteúdos) & $25 \%$ \\
\hline Falta de aceitação da escola e pais & 14,2 \\
\hline Falta de vontade do professor, falta de planejamento & 10,7 \\
\hline Cultura do silêncio; currículo centrado na escrita & 10,7 \\
\hline Indisciplina e agitação (todos os alunos falam ao mesmo tempo) & 10,7 \\
\hline
\end{tabular}

Fonte: elaborado pelas autoras

Nesses dados, podemos deduzir também uma concepção de supremacia da escrita, quando os docentes se referem a uma "cultura do silêncio", ao currículo centrado na escrita e à falta de aceitação da escola e dos pais. Isso revela que pouca importância é dada às práticas de oralidade tanto no currículo quanto no valor social que ela tem (escola e pais), de modo que a avaliação valorizada é pela escrita. A cultura do silêncio pode ser associada a uma resposta à indisciplina e à agitação.

Pareceu-nos, também, que a oralidade aqui foi tratada como conscientização, em que

Periódico Horizontes - USF - Itatiba, SP-Brasil - e019004 
uma resposta referia-se a "como é importante falar sobre a oralidade com os alunos"; isso aponta para uma educação em que basta abordar o tema, com poucas experiências reais com debates, palestras, exposições, entrevistas, bem como análise das interações das quais participaram, mas apenas "aprender sobre a língua" sem integração com "aprender pela língua em uso". Essa afirmação nos remete à compreensão da oralidade como tema, e não como uso e reflexão. Vemos, nessas respostas, coerência com a afirmativa de Dolz e Schneuwly:

Se, para as atividades gramaticais, o professor dispõe de uma descrição precisa dos conteúdos que os alunos devem adquirir a cada série; para as atividades de expressão escrita e oral, onde os saberes a se construir são infinitamente mais complexos, ele tem tido de se contentar com indicações muito sumárias. Tudo se passa como se a capacidade de produzir textos fosse um saber que a escola deve encorajar, para facilitar a aprendizagem, mas que nasce e se desenvolve fundamentalmente de maneira espontânea, sem que pudéssemos ensiná-la sistematicamente (DOLZ; SCHNEUWLY, 2004, p. 50 - grifos nossos).

Ainda vemos que são citadas, nas respostas, a falta de vontade do professor e a falta de organização e a possibilidade de tumulto com as atividades de oralidade, em que todos falam ao mesmo tempo. Nos relatos dos professores, a oralidade é tida como indisciplina. Todavia, sabemos que se os alunos puderem entender e participar de situações autênticas de interlocução, observando as interações orais, em atividades de escuta ativa/análise do texto oral; se puderem planejar a sua fala em função da situação interativa proposta, é provável que a participação seja efetiva em atividades organizadas e sistematizadas, assim como quando as regras de participação em papeis imbricados em diferentes gêneros orais são construídas coletivamente, conforme pesquisas com práticas pedagógicas já demostraram (ALVIM, 2015).

\section{Formação cidadã}

$\mathrm{Na}$ terceira questão, indagamos aos professores sobre quais seriam as possíveis consequências para os alunos caso uma educação para a oralidade fosse desenvolvida na escola. As respostas surpreendem pelo aspecto positivo que os professores revelaram, sendo o 
desenvolvimento e a formação cidadã uma crença da quase totalidade dos docentes, conforme os dados abaixo podem apontar:

Quadro 3 - síntese de respostas da questão 3

\begin{tabular}{|l|l|}
\hline Menos medo e vergonha, mais segurança e mais possibilidade de inserção social & $28,5 \%$ \\
\hline Alunos mais críticos, capacidade de argumentação, mais consciência, autonomia & $25 \%$ \\
\hline Melhor apropriação de conhecimento (mais desenvolvimento) & 10,7 \\
\hline Melhora na leitura e na escrita & 7,1 \\
\hline Mais trocas e relações melhores (professor - aluno) e mais próximas aos alunos & 7,1 \\
\hline Menos preconceito linguístico & $3,5 \%$ \\
\hline
\end{tabular}

Fonte: elaborado pelas autoras

Há ainda aspectos que colocam o desenvolvimento da oralidade em dependência da escrita $(7,1 \%)$ e da apropriação de conhecimentos, fruto, acreditamos, da tradição do letramento escolar. Conforme abordamos em nosso referencial, fala e escrita estão imbricadas e, então, não se trata de substituir ou suprimir as atividades de escrita, mas relacioná-las em projetos relevantes para a aprendizagem dos alunos.

\section{Gêneros orais e atividades recorrentes}

Os gêneros orais e as atividades mais recorrentes presentes nas práticas docentes, tanto dos que já vinham sugeridos no questionário ${ }^{10}$, quanto dos que foram acrescentados na opção "outros", foram os seguintes:

Quadro 4 - síntese de respostas da questão 4

\begin{tabular}{|l|l|}
\hline Seminário & $71,4 \%$ \\
\hline Leitura oral em sala & $71,4 \%$ \\
\hline Apresentação pessoal & $57,1 \%$ \\
\hline Resolução de exercícios na oralidade & $46,4 \%$ \\
\hline Debate & $42,8 \%$ \\
\hline Depoimento & $35,7 \%$ \\
\hline Notícias e reportagens orais (jornal) & $35,7 \%$ \\
\hline
\end{tabular}

${ }^{10}$ Essa sugestão foi construída com base na citação de gêneros e atividades recorrentes em outras pesquisas com professores, já citadas neste artigo.

Periódico Horizontes - USF - Itatiba, SP-Brasil - e019004 


\begin{tabular}{|l|l|}
\hline Entrevista & $32,1 \%$ \\
\hline Rodinha, música, jogos & $17,8 \%$ \\
\hline Sarau & $7,1 \%$ \\
\hline Tutorial & 0 \\
\hline
\end{tabular}

Fonte: elaborado pelas autoras

Vemos que o seminário é a prática oral mais realizada na escola, coincidindo com outras pesquisas, que revelam a recorrência deste gênero no ensino (GOULART, 2005; BUENO, 2008; SOARES, 2012, SILVA; SILVA, s/d.). É importante perceber que, embora seja um gênero recorrente na escolarização, isso não é garantia de efetiva aprendizagem, conforme alerta Bueno, quanto à questão:

(...) o seminário em si, enquanto um gênero textual, não é tomado como um instrumento a ser ensinado, o resultado das apresentações dos alunos nem sempre satisfaz a eles e ao professor. Afinal, como não dominam o gênero, é comum os alunos em uma situação de seminário irem para a parte da frente da sala de aula, ficarem parados diante dos colegas sem saberem como falar, como gesticular, como se posicionar, como olhar para as pessoas, etc. E como apresentam dificuldades para organizar previamente a apresentação, o conteúdo e a discussão que trazem dos textos sugeridos pelo professor fica também a desejar (BUENO, 2008, p. 2).

Além do seminário, debates e entrevistas, que também foram citados, devem não apenas ser abordados como instrumentos para interação, bem como objeto de estudo, descrição, análise, refacção, rumo ao domínio das operações de linguagem que constituem os gêneros.

Nossos dados mostram, também, que a atividade de leitura oral em sala é tomada como uma prática de oralidade; a resolução de exercícios oralmente também apresenta alta porcentagem; todavia, conforme vimos, o foco desta atividade é o tema de um texto, correção de exercício, mas o próprio gênero oral ou as reflexões sobre o uso da fala e de seus aspectos multimodais nas interações não são objeto de discussão, reflexão e sistematização. Assim, retornamos ao "basta falar", que coincide com o alto número de respostas da 1a questão (falar livremente) desta pesquisa.

Ainda que tenhamos visto certo avanço na presença de gêneros orais na escola, a

Periódico Horizontes - USF - Itatiba, SP-Brasil - e019004 
concepção predominante é a oralidade integrada a outras atividades, em que ela é reduzida a um "percurso de passagem para aprendizagem de outros comportamentos linguísticos (a escrita ou a produção escrita) ou não-linguísticos (em relação com outros saberes disciplinares)".

Há ainda mais algumas observações: consideramos pequena a presença de oralidade na relação com a literatura (sarau), com apenas $2 \%$ de ocorrências. Outra observação é a recorrência de trabalhos como "rodinha" na Educação Infantil. Essa resposta é relevante porque havia 19 professores que atuavam não apenas no Ensino Fundamental I (10 ao 5을 anos) mas também, até concomitantemente, em dois cargos, acumulando com a Educação Infantil. Assim, durante o curso, essa foi uma prática discutida e avaliada como relevante para a etapa, mas não suficiente para avançar em práticas mais diversificadas de oralidade, conforme os pressupostos teóricos aos quais nos vinculamos, defendem:

Não existe 'o oral', mas 'os orais' sob múltiplas formas, que, por outro lado, entram em relação com os escritos, de maneiras muito diversas: podem se aproximar da escrita e mesmo dela depender - como é o caso da exposição oral ou, ainda mais, do teatro e da leitura para os outros -, como também podem estar mais distanciados - como nos debates ou, é claro, na conversação cotidiana. Não existe uma essência mítica do oral que permitiria fundar sua didática, mas práticas de linguagem muito diferenciadas, que se dão, prioritariamente, pelo uso da palavra (falada), mas também por meio da escrita, e são essas práticas que podem e tornar objetos de um trabalho escolar (SCHNEUWLY, 2004, p. 135).

Como vemos, uma síntese desses dados permite perceber que a concepção predominante reforça a supremacia da escrita e o mito do letramento, de que a inserção social dos sujeitos na sociedade se dá apenas, ou de forma mais valorizada, pelo domínio da escrita, concepção que a escola reproduz historicamente. Para além dessa constatação, precisamos rever, nos cursos de formação inicial e continuada, as concepções de linguagem e oralidade que têm sido adotadas, para romper com esse quadro.

Periódico Horizontes - USF - Itatiba, SP-Brasil - e019004 


\section{Relatos de práticas: as tentativas de inovação na sala de aula}

Uma grande conscientização sobre a necessidade de incluir práticas de oralidade na escola foi vista no final do curso, em que os professores apresentaram oralmente seus projetos desenvolvidos nas escolas e entregaram um relato escrito. Essa etapa do curso de extensão foi bastante relevante, pois pudemos atestar a apropriação de conceitos discutidos ao longo do ano. As práticas mais relevantes relatadas pelos professores, no tema da oralidade, foram aqueles que justamente assumiram uma concepção de linguagem como prática social, propondo situações autênticas de interlocução por meio de gêneros orais na escola, em um ensino que envolveu uma proposta com preparação para a fala, estudo do gênero, produção, reflexão e consolidação da aprendizagem. Dois desses relatos merecem destaque, pois configuram-se como práticas de efetiva aprendizagem da língua.

No relato da professora de Educação Infantil "Rita", ela admitiu não ter, até aquele momento, consciência sobre o que fazer nesta etapa para fugir das tradicionais "rodinhas" de conversa, relatos orais e contação de histórias. Apoiando-se nesta última, a professora, após ler livro de literatura infantil com os alunos, de uma autora da cidade, instigou os discentes a entrevistar a autora da obra, já que ela iria à escola conversar com eles, caso quisessem. Os alunos, muito animados, sob orientação da professora, prepararam previamente uma entrevista oral: assistiram uma entrevista televisiva, discutiram como ela se estruturava (perguntas e respostas), elaboram perguntas, discutiram possíveis regras de comportamento e tipo de linguagem utilizada neste evento, bem como definiram a ordem das perguntas; fizeram, ainda, uma organização do evento, em que receberiam a convidada na escola. A autora, então, foi à escola, na qual foi recebida com carinho pelos pequenos aprendizes, que realizaram a entrevista da forma como planejado. Realizaram um agradecimento ao final, com um lanche e uma lembrancinha.

A professora, neste relato, ressaltou que a conscientização sobre a necessidade de propor momentos reais de interação, integrando escrita e oralidade, desde a educação infantil, foi central em sua prática, já que não tinha clareza sobre quais gêneros orais poderia propor para

Periódico Horizontes - USF - Itatiba, SP-Brasil - e019004 
alunos tão pequenos, fugindo das práticas cristalizadas.

Já o professor Wagner ${ }^{11}$, realizou um trabalho com os gêneros notícia e reportagem com alunos do Ensino Médio, no intuito de incluir mídias audiovisuais em seu trabalho, o que propiciou momentos de produção oral riquíssimos. $O$ docente trabalhou as relações entre esses dois gêneros na mídia televisiva e, também, questões relativas à opinião e informação, públicoalvo etc, além de ter, pela mídia televisionada, abordado questões de entonação, expressões faciais e corporais. Assim, os alunos criaram reportagens, com orientações de que fizessem um roteiro preliminar, atentassem para posicionamento corporal, enquadramento da câmera, linguagem clara, seriedade diante do vídeo, tom de voz moderado etc. Mesmo com algumas dificuldades no formato dos arquivos, ausência de roteiro, excessiva interação entre jornalista e entrevistado, volume baixo, enquadramento da câmera com problemas, os alunos envolveramse com o gênero reportagem e, ainda que com dificuldades, timidez e falta de alguns recursos e conhecimentos sobre edição de vídeos, o trabalho produziu envolvimento dos alunos de forma enriquecedora, o que proporcionou momentos de "descobertas e superação", segundo o professor. O professor Wagner, em outros momentos do curso, relatou também ter feito um trabalho com a mídia podcast na produção de propagadas com seus alunos do ensino fundamental, a partir de um projeto na escola, que também causa grande envolvimento dos estudantes.

\section{Considerações finais}

Após a finalização desta pesquisa, podemos perceber que há avanços consideráveis nas concepções e práticas pedagógicas descritas pelos docentes, uma vez que emerge do discurso docente a relevância do ensino de oralidade para a formação cidadã e a necessidade de proposição de situações interativas pelos gêneros orais na escola, este último não atestado na pesquisa de 2006. Além disso, vários gêneros orais já são citados como pertencentes às práticas

\footnotetext{
${ }^{11}$ Relato do professor intitulado "Letramento midiático por meio de gêneros jornalísticos", não publicado. Periódico Horizontes - USF - Itatiba, SP-Brasil - e019004
} 
pedagógicas dos docentes, que vão além do seminário, como as entrevistas, os debates, as notícias e reportagens, dentre outros. A indicação é que futuras pesquisas investiguem como isso se dá em sala de aula, contribuindo para descortinar as minúcias do trabalho docente.

Todavia, compreendemos que tais dados também revelam que ainda há esforços a empreender para o rompimento da compreensão da oralidade como conteúdo, em que se fala sobre sua importância, mas não se propõem situações de uso e reflexão. Vale destacar que ainda há crenças na supremacia da escrita e práticas calcadas no uso da fala para correção de exercícios e conversas livres.

Ressaltamos o alto número de professores que, por atestarem dificuldades pelas lacunas em seus cursos iniciais, reivindicam cursos formativos que os ensinem a trabalhar com práticas orais. Ademais, a ausência de equipamentos e dificuldades materiais se revelam aqui nesta pesquisa, como em outras também relatadas.

Tomamos, para finalizar, as palavras lúcidas de Chaves (2008), quando afirma que devemos ir além do discurso que apenas revele, ou mesmo cite em tom de denúncia, o trabalho docente. Como ela, vemos que "o diálogo entre a escola e a academia muito pode contribuir para o avanço da profissionalização e para a redução da proletarização do ensino na educação básica, em nosso país". Esses resultados apontam para trabalhos futuros em que universidade e escola pesquisem, colaborativamente, novas formas de desenvolver estratégias para o ensino de oralidade, envolvendo os gêneros digitais, por meio de mídias audiovisuais, e o sistema literário como prioridades.

\section{Referências}

ALVIM, V. T. Práticas de oralidade no ensino fundamental: características e funções das atividades de escuta. 2015. 187 p. Dissertação (Mestrado em Educação). Universidade Federal de Juiz de Fora, Juiz de Fora, 2015.

ÁVILA, E.; NASCIMENTO, G.; GOIS, S.. Ensino de oralidade: revisitando documentos oficiais e conversando com professores. In: LEAL, T. F.; GOIS, S. (orgs). A oralidade na escola: a investigação do trabalho docente como foco de reflexão. Belo Horizonte: Autêntica, 2012, p.37

Periódico Horizontes - USF - Itatiba, SP-Brasil - e019004 
$-56$.

BAUMGÄRTNER, C. T. Grupo de estudos de Língua Portuguesa - GELP: uma experiência de formação continuada de professores com foco nos gêneros orais e ensino. In: BUENO, L. COSTA-HÜBES, T. C. (orgs). Gêneros orais no ensino. Campinas-SP: Mercado de Letras, 2015, p. 91-116.

BUENO, L. Gêneros orais na escola: necessidades e dificuldades de um trabalho efetivo. Revista Instrumento. Juiz de Fora, v. 11, n. 1, jan./jun. p. 9 - 18, 2009.

BUENO, L. Gêneros orais: elementos linguísticos e não-linguísticos. In: I SIMELP -SIMPÓSIO MUNDIAL DE ESTUDOS DE LÍNGUA PORTUGUESA, 2008, São Paulo. Anais [...] São Paulo: USP, 2008. v. 1.

BUENO, L.; COSTA-HÜBES, T. C. (orgs). Gêneros orais no ensino. 1a ed. Campinas-SP: Mercado de Letras, 2015.

BUENO, L.; ABREU, C. de J. Gêneros orais na universidade: relato de uma experiência com o seminário. Bragança Paulista: Synergies Brésil, 2010. p. 119 - 125.

CHAVES, M. H. R. O gênero seminário escolar como objeto de ensino: instrumentos didáticos nas formas de trabalho docente. 2008. 184 p. Dissertação (Mestrado em Letras). Universidade Federal do Pará. Programa de Pós-Graduação em Letras. 2008.

CORRÊA, M. L. G. Letramento e heterogeneidade da escrita no ensino de português. In: SIGNORINI, I. (org). Investigando a relação oral/escrito e as teorias de letramento. Campinas: Mercado de Letras, 2001, p. 135 - 166.

COSTA-MACIEL, D. A. G. Os saberes docentes para o ensino do oral: o que sabem os docentes e como compreendem as atividades propostas pelos livros didáticos de língua portuguesa? 2011. 215 p. Tese (Doutorado em Educação). Universidade Federal de Pernambuco. 2011.

GALVÃO, M. A. M.; AZEVEDO, J. A. M. A oralidade em sala de aula de língua portuguesa: o que dizem os professores do ensino básico. Revista Filologia E Linguística Portuguesa, São Paulo, v. 17, n. 1, p. 249-272, jan./jun. 2015.

DOLZ, J.; SCNHEUWLY, B.; HALLER, S. O oral como texto: como construir um objeto de ensino. In: SCHNEUWLY, B.; DOLZ, J. Gêneros orais e escritos na escola. (trad. org. Roxane Rojo; Glaís Sales Cordeiro). Campinas, Mercado de Letras, 2004, p. 149 - 185.

DOLZ, J.; SCHNEUWLY, B. Gêneros e progressão em expressão oral e escrita: elementos para reflexões sobre uma experiência suíça (francófona). In: SCHNEUWLY, B.; DOLZ, J. Gêneros orais

Periódico Horizontes - USF - Itatiba, SP-Brasil - e019004 
e escritos na escola. (trad. org. Roxane Rojo; Glaís Sales Cordeiro). Campinas, Mercado de Letras, 2004, p. $41-70$.

GOULART, C. A exposição oral em seminário: um gênero escolar muito utilizado, mas pouco sistematizado. 2006. Disponível em: http://www.filologia.org.br/ileel/artigos/artigo_307.pdf. Acesso em: agosto de 2018.

KLEIMAN, A. Os estudos de letramento e a formação do professor de língua materna. Revista Linguagem Em (Dis)Curso, v. 8, n. 3, p. 487-517, 2008. Disponível em: http://www.scielo.br/pdf/ld/v8n3/05.pdf. Acesso em: maio de 2015.

LEAL, T. F.; BRANDÃO, A. C. P.; NASCIMENTO, B. E. S. Basta conversar? A prática de ensino da oralidade no segundo ciclo. In: HEINIG, Otília; FRONZA, Cátia de A. (orgs) Diálogos entre linguística e educação. Blumenau, Edifurb 2010, p. 91 - 114.

LEAL, T. F.; GOIS, S. A oralidade na escola: a investigação do trabalho docente como foco de reflexão. 1a ed. Belo Horizonte: Autêntica, 2012.

MACHADO, M. F. K. Um olhar sobre o cotidiano escolar: o eixo da oralidade nas práticas do(a) professor(a) alfabetizador(a) participante da formação do PNAIC em Santa Catarina. Revista Práticas de Linguagem. Vol. 7, n.1 - Especial Pacto Nacional pela Alfabetização na Idade Certa, p. 103 - 116, 2017.

MAGALHÃES, T. G. Oralidade na sala de aula: alguém 'fala' sobre isso? Revista Instrumento (Juiz de Fora), v. 7-8, p. 25-35, 2006.

MAGALHÃES, T. G.; FERREIRA, F. C. Proposta curricular de língua portuguesa: uma análise de documentos da cidade de Juiz de Fora (MG). Revista Signum Estudos de Linguagem, v. 17, p. 92-119, 2014.

MARCUSCHI, L. A. Da fala para a escrita: atividades de retextualização. 1a ed. São Paulo: Cortez, 2001.

MARCUSCHI, L. A. Oralidade e ensino de língua: uma questão pouco "falada". In: DIONÍSIO, M. Â. P.; BEZERRA, A. (orgs). O livro didático de Português: múltiplos olhares. 2 ed. Rio de Janeiro: Lucerna, 2003, p. 21 - 34.

MIRANDA, N. S. Educação da oralidade ou cala a boca não morreu. Revista Da Anpoll. São Paulo, n‥ 18, 159-182, jun, 2005. Disponível em:

https://revistadaanpoll.emnuvens.com.br/revista/article/view/445/454. Acesso em: fevereiro de 2011.

MOREIRA, H.; CALEFFE, L. G. Metodologia da pesquisa para o professor pesquisador. 2a ed. Rio

Periódico Horizontes - USF - Itatiba, SP-Brasil - e019004 
de Janeiro: DP\&A, 2006.

ONG, W. Oralidade e cultura escrita: a tecnologização da palavra. 1ạ ed. Campinas: Papirus, 1998.

PALMIERI, D. T. L. Concepções sobre o oral e seu ensino junto a professores em formação. In: ANAIS DO CONGRESSO DE LEITURA DE BRASIL. 2005. Acesso em: junho de 2016. Disponível em: http://alb.org.br/arquivo-morto/edicoes_anteriores/anais16/sem11pdf/sm11ss02_03.pdf

RANGEL, E. de O. Educação para o convívio republicano: o ensino de Língua Portuguesa pode colaborar para a construção da cidadania? In: Língua Portuguesa: ensino fundamental. Brasília: Ministério da Educação, Secretaria de Educação Básica, 2010.

ROJO, R.; SCHNEUWLY, B. As relações oral/escrita nos gêneros orais formais e públicos: o caso da conferência acadêmica. 3. ed. Tubarão: Universidade do Sul de Santa Catarina, 2006. 31 p. v. 6.

SCHNEUWLY, B. Palavra e ficcionalização: um caminho para o ensino da linguagem oral. In: SCHNEUWLY, B.; DOLZ, J. Gêneros orais e escritos na escola. (trad. org. Roxane Rojo; Glaís Sales Cordeiro). Campinas, Mercado de Letras, 2004, p. 129 - 148.

SILVA, W. M.; SILVA, M. C. Refletindo sobre o seminário: saberes e dissabores de uma prática letrada. In: IV SENALE. ANAIS [...] s./d.

SOARES, A. P. O. Gêneros acadêmicos: o caso dos textos orais produzidos na universidade. In: GELNE - GRUPO DE ESTUDOS LINGUÍSTICOS DO NORDESTE. ANAIS [...] 2012.

Recebido em Maio de 2018.

Aprovado em Outubro de 2018. 